\title{
Effects of toxic and non-toxic crude extracts on different Microcystis species (Cyanobacteria)
}

\section{Maria do Carmo Bittencourt-Oliveira ${ }^{1,2,3 \star}$, Danilo Camargo-Santos ${ }^{1,2}$, Ariadne do Nascimento Moura $^{3}$, Ingrid Bardini Francisco ${ }^{1}$, Carlos Tadeu dos Santos Dias ${ }^{4}$, Renato José Reis Molica and Micheline Kézia Cordeiro-Araújo ${ }^{1,3}$}

${ }^{1}$ Department of Biological Sciences, Luiz de Queiroz College of Agriculture, University of São Paulo, Av. Pádua Dias, 11, São Dimas, CEP 13418-900, Piracicaba, SP, Brazil.

${ }^{2}$ Graduating Program on Biological Sciences, São Paulo State University, UNESP, Av. 24-A, 1515, CEP 13506-900, Rio Claro, SP, Brazil.

${ }^{3}$ Graduating Program on Botany, Rural and Federal University of Pernambuco, R. Dom Manoel de Medeiros, S/N, Dois Irmãos, CEP 52171-030, Recife, PE, Brazil.

${ }^{4}$ Department of Exact Sciences, Luiz de Queiroz College of Agriculture, University of São Paulo, Av. Pádua Dias, 11, São Dimas, CEP 13418-900, Piracicaba, SP, Brazil.

${ }^{5}$ Graduating Program on Ecology, Rural and Federal University of Pernambuco, R. Dom Manoel de Medeiros, S/N, Dois Irmãos, CEP 52171-030, Recife, PE, Brazil.

Accepted 10 May, 2013

Our objective was to investigate crude extracts toxic $(\mathrm{MC}+)$ and non-toxic (MC-) effects on the growth of Microcystis panniformis, Microcystis aeruginosa and Microcystis wesenbergii. Cultures were submitted to extracts $\mathrm{MC}+$ at 5 and $10 \mathrm{MC} \mu \mathrm{g} \cdot \mathrm{L}^{-1}$, and to MC- equivalent weight of these concentrations. Both crude extracts worked toward reducing the growth of $M$. wesenbergii and stimulating the growth of $M$. panniformis. Likewise, $M$. aeruginosa was inhibited by addition of crude MC- extract. The action of microcystins at concentrations commonly found in natural environments, plus the presence of other substances in intracellular $M$. aeruginosa produced differentiated effects in Microcystis spp.

Key words: Microcystis aeruginosa, Microcystis panniformis, Microcystis wesenbergii, allelopathy, crude extract, microcystin, phytoplankton, toxin.

\section{INTRODUCTION}

Microcystins (MCs) are known as highly toxic secondary metabolites which may be produced by cyanobacteria that commonly form blooms (Sivonen and Jones, 1999). Experimental studies show that substances like MC have allelopathic effects on direct competitors of cyanobacteria such as microalgae and aquatic plants (Kearns and
Hunter, 2001; Pflugmacher, 2004). Allelopathy is a set of biochemical interactions, stimulating or inhibitory, between bacteria, fungi, algae or plants in a target organism (Rice, 1984). On the other hand, there are a few studies indicating that MCs has allelopathic effects on aquatic macrophytes (Pflugmacher, 2002, 2004), terrestrial plants 
(Peuthert et al., 2008), zooplankton (Ferrão-Filho and Azevedo, 2003), phytoplankton (Suikkanen et al., 2005; Sedmak and Elersek, 2005; Babica et al., 2007) and cyanobacteria (Sedmak and Kosi, 1998; El Sheekh et al., 2010). Overall, allelopathic effects encompass biochemical interactions, involved both in stimuli and growth inhibition, among diverse primary producers or among these and microorganisms (Rice, 1984). Zilliges et al. (2011) shown that MC could be attached to the intracellular proteins of cyanobacteria increasing, in this way, the life time of these molecules. In this sense, it might well be possible that $\mathrm{MC}$ is able to stimulate the enhancement of cyanobacteria cellular density, which could favor the reproduction of certain Microcystis strains (MC producing or not). Moreover, growth inhibition of other phytoplanktonic organisms could take place, a circumstance that could help dominance enforcement of Microcystis blooms.

There are few studies revealing the effects of microcystins at concentrations typically found in natural environments (Kearns and Hunter, 2001). However, a greater number of studies showed altered growth of phytoplankton species caused by microcystins when subjected to high concentrations not usually found in the environment (Sedmak and Kosi, 1998; Suikkanen et al., 2004; Babica et al., 2007; El Sheekh et al., 2010). The concentration of dissolved microcystins in aquatic ecosystems is in general less than $10 \mu \mathrm{g} \cdot \mathrm{L}^{-1}$, except during the break down of blooms (Sivonen and Jones, 1999). Therefore, our objective was to investigate crude extracts toxic $(\mathrm{MC}+)$ and non-toxic (MC-) effects, on the growth of Microcystis panniformis Komárek, Komárková-Legnerová, Sant'Anna, Azevedo and Senna, Microcystis aeruginosa (Kützing) Kützing and Microcystis wesenbergii (Komárek) Komárek, at concentrations similar to those found in natural environments.

\section{MATERIALS AND METHODS}

\section{Strains and culture conditions}

The $M$. aeruginosa BCCUSP232 strain produces MC-LR and MCRR according to Bittencourt-Oliveira et al. (2011). On the other hand, $M$. aeruginosa BCCUSP03, M. panniformis BCCUSP200 and $M$. wesenbergii BCCUSP11 are non microcystin-producing (Bittencourt-Oliveira, 2003). All strains were clonal and non-axenic, belonging to the Brazilian Cyanobacteria Collection of the University of São Paulo. All cultures were grown as batch cultures maintained in BG-11 or ASM-1 medium, pH 7.4, according to Rippka et al. (1979) and Gorham et al. (1964), respectively, in climatic chambers with controlled conditions of light $\left(40 \mu \mathrm{mol} \cdot \mathrm{m}^{-2} \cdot \mathrm{s}^{-1}\right.$, using photometer with spheric subaquatic sensor LI-COR, mod. LI-250), photoperiod $\left(14: 10 \mathrm{~h}\right.$ light:dark) and temperature $\left(24 \pm 0.5^{\circ} \mathrm{C}\right)$. The irradiance was measured in the center of the incubating flasks. Flasks positions inside the climatic chamber were intertwined in order to smooth out data fluctuations.

\section{Obtaining crude extracts and quantification of microcystins}

Twenty liters $(20 \mathrm{~L})$, approximately of M. aeruginosa BCCUSP232 (microcystin-producing strain) and M. aeruginosa BCCUSP03 (no microcystin-producing strain) cultures were cultivated. The resulting culture media were centrifuged, frozen in liquid nitrogen, lyophilized and stored in a $-80^{\circ} \mathrm{C}$ freezer until further use. The lyophilized biomass $\left(0.045\right.$ to 10 and $0.022 \mathrm{~g}$ to $5 \mathrm{MC} \mu \mathrm{g} \cdot \mathrm{L}^{-1}$ was resuspended in approximately $1 \mathrm{~mL}$ of deionized water and ultrasonicated (Microson Ultrasonic Cell Disruptor, Misonix, USA) for 5 min (15 W and $22.5 \mathrm{kHz}$ ) for the disruption of cells. From crude extracts of BCCUSP232 (MC+) strain, concentrations of 5 and $10 \mathrm{MC} \mu \mathrm{g} \cdot \mathrm{L}^{-1}$ were obtained and used in the treatments. The BCCUSP03 strain lyophilized biomass has the equivalent weight used with the BCCUSP232. The MCs were quantified using a commercial Enzyme-Linked Immuno Sorbent Assays (ELISA) kit (Beacon Analytical Systems, Inc., Portland, ME, USA) and analyses were carried out in triplicate.

\section{Experiments}

All experiments and controls were prepared in $1000 \mathrm{~mL}$ Erlenmeyer - flasks with $600 \mathrm{~mL}$ of culture medium in triplicate, and maintained in the conditions aforementioned. For each experiment, $1.0 \times 10^{5}$ cell. $\mathrm{mL}^{-1}$ were used as the initial cellular density (day 0 ). The crude

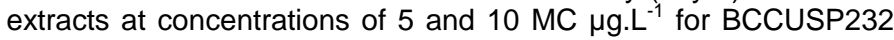
(MC+) and their equivalent biomass for BCCUSP03 (MC-) were added at the fourth day of experiments. A $2 \mathrm{~mL}$ sample was picked up from all cultures (control and treatments) every 2 days and preserved with acetic lugol $10 \%$. The cellular densities were estimated by counting using a Fuchs Rosenthal hemocytometer and a binocular optical microscope (Nikon E200, Melville, NY, USA) at 400x magnification, according to Lund et al. (1958) to a 5\% error level.

\section{Statistical analyses}

The cell density data were tested for normality and homogeneity of variances and, afterward, to an analysis of variance (ANOVA) using repeated measurements as to determine significant differences between target cultures strains treated with crude extracts $(\mathrm{MC}+$ and MC-) and controls, along all experiments. Once differences were observed, we carried out a Tukey test to determine which treatments were significantly different, among them and relatively to the control. The significance was $5 \%$ for all tests and all data. All data were presented as averages with their corresponding standard deviations.

\section{RESULTS AND DISCUSSION}

Crude extracts of microcystins act differently in the three species of Microcystis (Figure 1a to f). The MC+ and MCextracts reduced the cellular density of $M$. wesenbergii (BCCUSP11) but increased in $M$. panniformis (BCCUSP200). However, M. aeruginosa (BCCUSP03) strain was inhibited by the MC- extract and was stimulited by the $\mathrm{MC}+$ one. Both crude extracts, $\mathrm{MC}+$ and $\mathrm{MC}$ worked toward reducing the cellular densities of $M$. wesenbergii (BCCUSP11) after addition of extracts in the fourth day, being significant from experiment day 10 on $p$ $<0.05$. The concentrations of 5 and $10 \mathrm{MC} \mu \mathrm{g} \cdot \mathrm{L}^{-1}$ showed similar results (Figure 1a to b). Likewise, M. aeruginosa (BCCUSP03) was inhibited by addition of crude extract MC-, being significant from $8^{\text {th }}$ day on $p<0.05$ and more evident at $10 \mathrm{MC} \mu \mathrm{g} \cdot \mathrm{L}^{-1}$. With the extract MC- at $5 \mathrm{MC}$ 

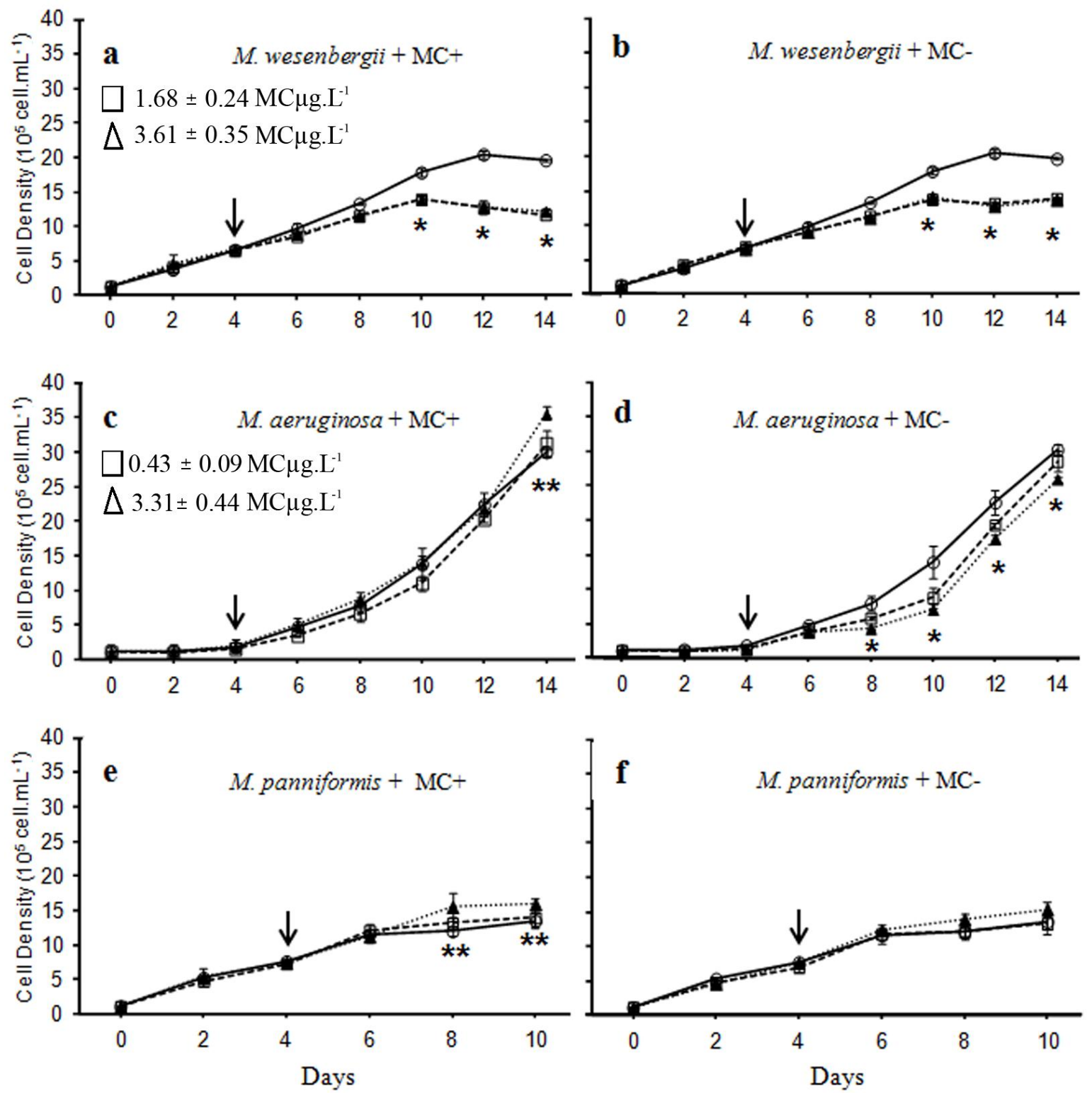

Figure 1. Microcystis spp. growth with addition of crude extracts of Microcystis aeruginosa BCCUSP232 (MC+) and M. aeruginosa BCCUSP03 (MC-). (a-b) M. wesenbergii BCCUSP11; (c-d) M. aeruginosa (BCCUSP03); (e-f) M. panniformis BCCUSP200. (*) Significant statistical difference between the treatments 5 and $10 \mathrm{MC} \mu \mathrm{g} \cdot \mathrm{L}^{-1}$ and control. $\left(^{* *}\right)$ Significant statistical difference between treatment with $10 \mathrm{MC} \mu \mathrm{g} \cdot \mathrm{L}^{-1}$ and control. The arrow indicates the day of crude extracts addition. MC concentrations used: $5 \mathrm{MC} \mu \mathrm{g} \cdot \mathrm{L}^{-1}(\mathbf{-}-\mathbf{- -})$ and $10 \mathrm{MC} \mu \mathrm{g} \cdot \mathrm{L}^{-1}(\cdots \mathbf{-} \cdot \cdots)$ and Control $(-)$. Error bars refer to standard deviation $(n=3)$. ( ) A $\square$ rage and standard deviation of microcystin concentrations at the $14^{\text {th }}$ day of the experiment with treatment with $5 \mathrm{MC} \mu \mathrm{g} \cdot \mathrm{L}^{-1}$. ( $\quad$ average and standard deviation of microcystin concentrations at the $14^{\text {th }}$ day of the experiment with treatment with $10 \mathrm{MC} \mu \mathrm{g}^{-1}$.

$\mu \mathrm{g} \cdot \mathrm{L}^{-1}$, the strain only recovered its growth on the $14^{\text {th }}$ day of the experiment. Intriguing however, for the crude extract $\mathrm{MC}+$, there was an increasing tendency of the cellular density with $10 \mathrm{MC} \mu \mathrm{g} \cdot \mathrm{L}^{-1}$, turning out to be evident on day $14^{\text {th }}$ of the experiment (Figure $1 \mathrm{c}$ to $\mathrm{d}$ ) and with a significant difference. On the other hand, $M$. panniformis (BCCUSP200) behaved differently from the other two species, putting in evidence cellular density increasing stimulation from both $\mathrm{MC}+$ and $\mathrm{MC}$ - crude extracts, and showing significant cellular density differen- 
ces at the 8th day of the experiment $(p<0.05)$ at $10 \mathrm{MC}$ $\mu g . L^{-1}$ (Figure 1e to f). Although, extracts do act on the cellular density a few days after their application, one could not state that earlier physiologic effects driven by cellular metabolism did not take place, since these were not scrutinized in this work.

Cellular density variations (increase or decrease) in the three species of Microcystis following addition of MCcrude extracts indicated that there are other substances with presumable allelopathic effects acting on the growth of these species. This fact confirms the results found by El-Sheekh et al. (2010), where a cellular density increase of the cyanobacteria Oscillatoria angutissima West and West and Anabaena sp., and of the green microalgae Chlorella vulgaris Beijerinck, was reported. In this case, a cell-free filtrate from a culture of $M C$ producing $M$. aeruginosa was used. However, this cell-free filtrate inhibited the Scenedesmus obliquus (Türpin) Kützing cellular density. Schagerl et al. (2002) and Gross (2003) put in evidence the possibility that cyanobacteria could produce compounds able to stimulate their own growth, and/or inhibit growth of other species. In this sense, by orchestrating acting with abiotic factors, the production of these compounds (MCs included) by Microcystis would work synergistically as a "trigger", such that one or more strains could reach dominance over the phytoplanktonic community. Although, Babica et al. (2007) and B-Beres et al. (2012) stated that an allelopathic character of the MCs seem to be lacking; Sedmak and Elersek (2005) pointed out that the ecologic role of the MCs could be different for the producing individuals and for those having contact with the toxin in the aquatic environment. Under this circumstance, it is possible that the MCs be an element of unknown communication routes among diverse toxic and/or non toxic strains of Microcystis (Vassilakaki and Pflugmacher, 2008) as well as for other organisms of the phytoplanktonic community. Also, by interacting with other substances and/or other abiotic factors (B-Beres et al., 2012), the MCs favor dominance of certain strains.

The process of allelopathy in cyanobacteria may be less frequent with low cell densities, which is the opposite of what occurs in blooms with high biomass (Leão et al., 2009). The suggestion that some cyanobacteria release autostimulatory (Monahan and Trainor, 1970; Suikkanen et al., 2005) or quorum-sensing compounds (Swift et al., 1994), which accelerated the growth of the same and related species was not confirmed in our study. The hypothesis that natural concentrations of cyanotoxins have allelopathic effects has not yet been confirmed, since most studies have used high concentrations that are unusual in aquatic ecosystems (Sedmak and Kosi, 1998; Babica et al., 2006). In conclusion, the action of microcystins and other substances present in intracellular M. aeruginosa (BCCUSP232 and BCCUSP03), in concen- trations normally found in natural environments, produced differentiated effects in species of Microcystis.

\section{ACKNOWLEDGEMENTS}

This research was supported by grants from FAPESP (Proc. 2011/50840-0, 2011/02957-5) and CNPq (301739/2011-0).

\section{REFERENCES}

Babica P, Bláha L, Marsalek B (2006). Exploring the natural role of microcystins - A review of effects on photoautotrophic organisms. J. Phycol. 42(1):9-20.

Babica P, Hilscherová K, Bártová K, Bláha L, Marsálek B (2007). Effects of dissolved microcystins on growth of planktonic photoautotrophs. Phycologia, 46(2):137-142.

B-Beres V, Grigorszky I, Vasas G, Borics G, Várbíró G, Nagy AS, Borbély G.,Bacsí I (2012). The effects of Microcystis aeruginosa (cyanobacterium) on Cryptomonas ovata (Cryptophyta) in laboratory cultures: why these organisms do not coexist in steady-state assemblages?. Hydrobiologia, 691(1):97-107.

Bittencourt-Oliveira MC (2003). Detection of potential microcystinproducing cyanobacteria in Brazilian reservoirs with a mcyB molecular marker. Harmful Algae 2(1):51-60.

Bittencourt-Oliveira MC, Oliveira MC, Pinto E (2011). Diversity of microcystin-producing genotypes in Brazilian strains of Microcystis (Cyanobacteria). Braz. J. Biol. 71(1):209-216.

El-Sheekh MM, Khairy HM, El-Shenody RA (2010). Allelopathic effects of cyanobacterium Microcystis aeruginosa on the growth and photosynthetic pigments of some algal species. Allelopathy $\mathrm{J}$. 26(2):275-290.

Ferrão-Filho AS, Azevedo SMFO (2003). Effects of unicellular and colonial forms of toxic Microcystis aeruginosa from laboratory cultures and natural populations on tropical cladocerans. Aquat. Ecol. 37(1): 23-35.

Gorham PR, Mclachlon JR, Hammer VT, Kim WK (1964). Isolation and culture of toxic strains of Anabaena flos-aquae (Lyngb.). Breb. Verh. Int. Ver. Limnol. 15:796-804.

Gross EM (2003). Allelopathy of aquatic autotrophs. Crit. Rev. Plant. Sci. 22:313-339.

Kearns KD, Hunter MD (2001). Toxin-producing Anabaena flos-aquae induces settling of Chlamydomonas reinhardtii, a competing motile alga. Microb. Ecol. 42(1):61-80.

Leão PN, Vasconcelos MTSD, Vasconcelos VM (2009). Allelopathic activity of cyanobacteria on green algae at low densities. Eur. J. Phycol. 44(3):347-355.

Lund JWG, Kipling C, Lecren ED (1958). The invert microscope method of estimating algae numbers and statistical basis of estimations by counting. Hydrobiologia 11(2):143-170.

Monahan TJ, Trainor FR (1970). Stimulatory properties of filtrate from the green alga, Hormotila blennista. I. Description. J. Phycol. 6(3):263-269.

Peuthert A, Lawton L, Pflugmacher S (2008). In vivo influence of cyanobacterial toxins on enzyme activity and gene expression of protein phosphatases in alfafa (Medicago sativa). Toxicon. 52(1):8490.

Pflugmacher S (2002). Possible allelopathic effects of cyanotoxins, with reference to microcystin-LR, in aquatic ecosystems. Environ. Toxicol. 17(4):407-413.

Pflugmacher S (2004). Promotion of oxidative stress in the aquatic macrophyte Ceratophyllum demersum during biotransformation of the cyanobacterial toxin microcystin-LR. Aquat. Toxicol. 70(3):169-178.

Rice EL (1984). Allelopathy. New York: Academic Press. 
Rippka R, Deruelles J, Waterbury JB, Herdman M, Stanier RY (1979). Generic assignments, strain histories and properties of pure cultures of cyanobacteria. J. Gen. Microbiol. 111(1):1-61.

Schagerl M, Unterrieder I, Angeler DG (2002). Allelopathy among Cyanoprokaryota and other algae originating from lake Neusiedlersee (Austria). Int. Rev. Hydrobiol. 87(4):365-374.

Sedmak B, Kosi G (1998). The role of microcystins in heavy cyanobacterial bloom formation. J. Plankton Res. 20(4):691-708.

Sedmak B, Elersek T (2005). Microcystins induce morphological and physiological changes in selected representative phytoplanktons. Microb. Ecol. 51(2):508-515.

Sivonen K, Jones G (1999). Cyanobacterial toxins. In: Chorus I, Bartram J (eds) Toxic Cyanobacteria in Water. A Guide to Their Public Health Consequences, Monitoring and Management. London: E and FN Spon, pp.41-111.

Suikkanen S, Fistarol GO, Graneli E (2004). Allelopathic effects of the baltic cyanobacteria Nodularia spumigena, Aphanizomenon flosaquae and Anabaena lemmermannii on algal monocultures. J. Exp. Mar. Biol. Ecol. 308(1):85-101.
Suikkanen S, Fistarol GO, Granéli E (2005). Effects of cyanobacterial allelochemicals on a natural plankton community. Mar. Ecol. Prog. Ser. 287:1-9.

Swift S, Bainton NJ, Winson MK (1994). Gram-negative bacterial communication by $\mathrm{N}$-acyl homoserine lactones: a universal language?. Trends Microbiol. 2(6):193-198.

Vassilakaki M, Pflugmacher S (2008). Oxidative stress response of Synechocystis sp. (PCC6803) due to exposure to microcystin-LR and cell-free cyanobacterial crude extract containing microcystin-LR. J. Appl. Phycol. 20(3):219-225.

Zilliges Y, Kehr J, Meissner S, Ishida K, Mikkat S, Hagemann M, Kaplan A, Börner T, Dittmann E (2011). The cyanobacterial hepatotoxin microcystin binds to proteins and increases the fitness of Microcytis under oxidative stress conditions. Plos One 6:e17615. 